\title{
Using action research to teach students to manage team learning and improve teamwork satisfaction
}

\author{
BRENDA SCOTT-LADD Murdoch University, Australia \\ CHRISTOPHER C. A. CHAN York University, Canada
}

\begin{abstract}
This article reports on a study investigating strategies that students can use to develop skills in managing team learning. Two groups of second-year management students participated in a semesterlong action research project over two semesters. The students were educated on team development, team processes and conflict management and how to review and enhance team development. Teaching staff supported the approach and students were regularly encouraged to reflect on and learn about how their behaviour contributed to team effectiveness. This approach encouraged student participation and ownership as well as early intervention if problems arose. Findings suggest that when students are taught to manage the processes of teamwork and take greater ownership of managing conflict and team relations they report less conflict and less social loafing and are more satisfied with their learning outcomes.
\end{abstract}

KEYWORDS: action research, collectivism, conflict management, learning styles, team development, teamwork

\section{Team learning}

Tertiary educators have adopted teamwork strategies to improve educational outcomes and prepare students for working in industry (Billet, 2004). Team learning has a number of positive pedagogical and practical benefits. Firstly, the team environment promotes cooperation and collaborative skill development (Portwood, 1999; Yazici, 2005) and teaches valuable interpersonal 
skills required in students' working lives (Mutch, 1998). Secondly, exploring information together encourages students to take greater ownership of their learning (Towns et al., 2000). Thirdly, sharing knowledge helps students learn from each other and develops a community of learning (Towns et al., 2000). Benefits also come from providing a relatively safe environment to test relationships and improve communication, conflict resolution and negotiation skills, which in turn builds self-efficacy, self-worth and adaptability (Portwood, 1999). Team discussion encourages students to explore different perspectives about content. Specific information or experiences on how to implement processes help them develop problem solving and critical thinking skills (Mutch, 1998). The benefits of team learning are borne out in a meta-analysis of 39 studies into small team learning conducted by Springer et al. (1999). Effective team members feel connected to each other, with a sense of working toward a shared, time-bounded goal (Ohl and Cates, 2006). Cohesive teams recognize their interdependence and accept responsibility for sharing and completing any given task (Wageman and Frederick, 2005).

However, the reality for many students falls short of this. Some researchers question whether teamwork benefits educational outcomes because of the problems that can arise (Mutch, 1998; Ohl and Cates, 2006). Problems usually arise across three categories: the team process, member expectations and the logistics of coordinating activities (Towns et al., 2000). Management processes are critical for success and should take into account task design, member roles, conflict, coordination, leadership, member expectations and conflicting personal agendas (Ohl and Cates, 2006; Towns et al., 2000). Confronting these in the formative stages minimizes problems. Differing expectations or perceptions about assessment requirements (Anderson, 2005), learning objectives, or the need to balance study, work and family roles, can cause problems. The logistics of coordinating timetables, meeting times, workloads and managing technology incompatibilities pose other challenges, so size is also important (Lou et al., 1996). Any of these can precipitate conflict or perceptions of loafing and lead to a breakdown in the team's performance.

The perception that some individuals are putting in less effort than others is referred to as social loafing or free riding (Butterfield and Pendegraft, 1996; Karau and Hart, 1998). Because individuals are less identifiable in teams they can hide behind other team members and this leads to perceptions of inequity that give rise to tension, conflict and de-motivation (Guerin, 2003). Wagner (1995) suggests that free riding is less likely among collectivists because they will put the team's needs ahead of their own. This contrasts with individualists, who are more focused on their own needs and less concerned about others (Triandis, 1995). Notions of 
individualism and collectivism draw on the cultural dimensions of Hofstede (Triandis, 1995) and suggest that individuals have different preferences within cultures. Individualists are less willing to risk academic achievements that maximize their employment prospects. On the other hand, collectivists will accept an individual loss to maintain harmony, which advantages them in team learning situations. For example, in McFeeters' (2003) study of 207 graduate students from differing cultures, collectivists achieved deeper learning outcomes. Students recognize that members can capitalize on each other's strengths. Nonetheless, the reality is that different team motivators and penalties apply in the workforce (Butterfield and Pendegraft, 1996). Implementing similar strategies to industry, such as having small-sized teams, allowing members to have specialized tasks and building-in ways of promoting cohesion as well as measuring individual performance outcomes can be of assistance (Karau and Hart 1998; McShane and Travaglione, 2005).

\section{Setting up and managing teamwork}

The literature has long identified that team members need to understand how teams develop, the different roles members adopt and how to deal with conflict so they can set up processes to manage the relationship and task interactions. Tuckman's model proposes teams go through five developmental stages: forming, storming, norming, performing and adjourning (Tuckman and Jensen, 1977). The first three stages lay the foundations for a working relationship to negotiate performing and adjourning. In contrast, Gersick's (1991) model of team development demonstrates the importance of balancing the task and member relationships. Having an agreed set of rules helps to shape effective norms, as the rules set out operating boundaries, specific actionable steps, a review process and dispute resolution process, similar to that practised in industry (Mutch, 1998). The rules hold members accountable to agreed (but flexible) boundaries and provide checkpoints, as recommended by Kahn (1995) and Knabb (2000). Establishing a dispute resolution process encourages discussion about what is likely to lead to conflict. In addition, it provides an opportunity to present conflict as a healthy process to improve decision-making and debate, in preference to viewing conflict as caused by problem members or problems needing to be pushed aside. The challenge is how to implement these strategies in a way that encourages the students to own these processes.

Having a good understanding of the processes that make a group successful and how to manage conflict may help members better manage team relationships. They also need to appreciate what each member brings to the 
team. Kolb's (1984) experiential learning model allows students to understand the learning process (Karau and Hart, 1998) and highlights the relationship between team members who lack experience and the difficulty of generalizing and applying learning. Honey and Mumford's (1995) extension of Kolb's model, which classifies preferences for doing, observing, feeling and thinking, may help students in working effectively in teams as this assesses their learning preferences. Honey and Mumford's (1995) approach describes learners as accommodators (learn by doing and feeling), divergers (learn by observing and feeling), convergers (learn by doing and thinking) and assimilators (learn by observing and thinking). These models and student expectations are the basis of establishing norms or rules for working together. The rules need to include a process for managing any conflict that might arise.

Having guidelines and processes to shape relationships and manage the task makes better outcomes achievable (Wageman, 1999). This is often where the process breaks down in the academic setting, and many students report having at least some negative experiences of working in teams. In part, this may occur because the focus is on content and the pressure to achieve outcomes overrides the importance of developing process skills. The benefits of using team-building strategies, such as self-disclosure, knowledge sharing and conflict management, to develop and strengthen relationships are known (Wageman and Frederick, 2005). However, this requires that students not only understand processes, but also have the skills, time and support to manage these processes. Although the models proposed by Kolb (1984) and the extension of this by Honey and Mumford (1995) have long been available, these have not been extensively tested against how students themselves view their experiences of teamwork.

Giving students practical skills for building team cohesion and managing team processes has received little attention in the tertiary education literature. If we are to better assist our students to diagnose, evaluate and plan changes to their team processes, we need to better understand how students monitor and shape their progress and we need to recognize the individual differences and strengths that contribute to learning outcomes. Given the importance of teamwork satisfaction, conflict management and having group rules and processes to manage the teamwork, understanding these and other factors and processes will enable us to better set up teamwork projects. In the study described below, we sought to find out whether making students more aware of the processes needed for successful teamwork would positively correlate with teamwork satisfaction and whether this would in turn increase satisfaction with the course overall. 


\section{Methodology}

An action research method as described by Towns et al. (2000) and Kuit et al. (2001) was used. Progress was reviewed and monitored by staff as well as students, and feedback informed any adaptations, as recommended by Diamond (2004) and Kuit et al. (2001).

\section{Procedure}

Data were collected from two classes of second-year undergraduate students over a two-year period. Data were collected at the first and final workshop of a sixteen-week semester, with thirteen contact weeks. Data collected at the beginning of each semester helped students identify the strengths and weaknesses individuals brought to teams, and strategies they could use to improve teamwork. Students considered their roles, individual attributes and stages of team development. Data collected at the end of the semester provided feedback on satisfaction with team performance and conflict management after participation. Student feedback from the first semester of the study informed adaptations to the course management in the second semester of the study.

At the beginning of the first semester of the study, 196 students participated (107 males and 89 females). Of these, 151 students were studying in Australia and 45 were in Malaysia. At the end of the semester, 164 surveys were returned; of these 131 responses from Australia and 21 responses from Malaysia were matched across time. The following year a different cohort of students participated in the study, and again data were collected at the beginning and end of semester. The second data set was smaller with 114 (59 female and 55 male) students responding to the first survey and 99 (53 female and 46 male) responding to the second survey. This second group comprised only Australian students. Responses were captured on Likert type scales, where $1=$ very negative, $3=$ neutral/unsure and $5=$ very positive. Students were given random, sequential secret numbers (these were written on the inside cover of the course guides) to protect confidentiality and allow data sets to be matched across the semester. Students retained copies of their responses so they could compare their results to the class aggregate and other students.

\section{Measures}

The first set of data measured 56 items. Fifteen items measured preferences for competing, collaborating, avoiding, accommodating and compromising, and these were taken from an abbreviated version of Rahim's (1983) instrument. An example question is 'I will negotiate so that a compromise can be reached'. Collectivism versus individualism was measured using 
five items per scale, from Triandis (1995). For example, an individualism question was 'I do better work by myself'; a collectivist question was 'I like to be able to access the ideas of other people to add to my own'. Cooperation versus independence was measured with two eight-item scales from Barnes and Owens (1992). A cooperation question was 'It is important for me to maintain harmony within my team', while an independence question was 'I think competition is the law of nature'. Learning style preferences were measured with ten paired items, adapted from Kolb (1984) as cited in Lussier and Poulos (1998). Respondents weighted preferences for observing, doing, feeling and thinking. For example, a measure for observing was 'I am careful' and a measure of doing was 'I am practical'. In addition five demographic questions regarding age range, gender, campus, work experience and whether studying full-time or part-time were included.

The second data set excluded measures found to be insignificant or problematic from the previous year. Measures of independence, collectivism and cooperation did not explain variances in the first study so these were substituted with questions about role attributes. Individual perceptions about leadership, communication, interpersonal and problem-solving abilities and aspirations (Brown and Harvey, 2006) were elicited with five questions each. The demographic questions were also included.

\section{End of semester survey for both groups}

The end of semester survey for both years contained 13 items measuring team member satisfaction with learning and conflict management.

\section{Results}

An examination of the means and standard deviations for responses in the first year of the study indicated that students had a greater preference for cooperation (mean 3.79) over independence (mean 2.78), and collectivism (mean 4.06) over individualism (mean 2.83). The remaining scales allowed forced choice responses, and so are reported as composite means. The preferred conflict handling style was for collaborating (mean 11.6), closely followed by compromising (mean 11.1), accommodating (mean 10.6) competing (mean 9.7) and lastly avoiding (mean 8.3). Learning style means indicated a higher preference for thinking (mean 14.42), followed by observing (mean 13.04), doing (mean 12.07) and feeling (mean 10.73). Reliabilities for the composite scale measures were close to or above Cronbach Alpha benchmark of 0.7, although, as Hair et al. (1998) point out, values close to this can be accepted, particularly in an exploratory study. The highest reliability was 0.71 for individualism and the lowest was 0.65 
for independence. No significant differences in relation to age, gender, location or whether studying full-time or part-time were identified between all respondents and the matched sample.

Between-group t-tests were undertaken to examine for significant differences between the Malaysian and Australian students, or between males and females. Simply explained, the t-test identifies differences in the ratio of responses between two groups to identify if differences are sufficiently large to be considered non-random or significant (Hair et al., 1998). The only significant difference was that female students indicated a higher preference for a feeling style, as indicated by a probability (p) value of $p \leq 0.05$, showing this exceeded a $95 \%$ probability of not being a random result. Cluster analysis indicated that having an observing learning style preference was opposed to having a doing style, whereas the feeling style was opposed to a thinking style. The normalized data showed learning preferences across the four categories were evenly distributed and no category had a greater influence on satisfaction with learning outcomes.

Next, a correlation analysis of the matched data collected at the start and end of semester was undertaken. This indicated that females, who had a somewhat higher preference for collectivism and integration than males, were more likely to access course information from the WebCT platform on the Internet. Students reported that Internet access to course material and recordings of the weekly lectures helped them manage the team process by clarifying information about course content and processes. Being able to manage the team processes and conflict resolution had a significant correlation to course and teamwork satisfaction, providing initial support for our hypothesis. As expected, working and older respondents were more likely to be studying part-time, and those with high levels of independence had reduced preferences for teamwork. The results of the correlation analysis are shown in Table 1.

Results from the second year of the study indicated students rated themselves most highly for interpersonal and communication skills, followed by aspiration, problem-solving skills, and leadership skills. Cronbach Alpha $(\alpha)$ reliabilities were highest for Leadership $(\alpha=0.75)$, Problem Solving $(\alpha=0.73)$ and Aspirations $(\alpha=0.68)$. Although lower, reliabilities for Communication and Interpersonal skills $(\alpha=0.65)$ were still acceptable. Correlations between the traits imply that aspiration and interpersonal skills were the only attributes not significantly related. Independent sample t-tests show males rated their attributes as leaders $(p \leq 0.01)$, being more independent, with better interpersonal and problem-solving skills $(p \leq 0.05)$, significantly higher than females. 
Table 1 Correlation analysis for matched data sample, 2004

\begin{tabular}{|c|c|c|c|c|c|c|c|c|c|c|}
\hline & Gender & $\begin{array}{l}\text { Study } \\
\text { full/part } \\
\text { time }\end{array}$ & $\begin{array}{l}\text { Access } \\
\text { Web CT }\end{array}$ & Observing & Feeling & Thinking & Cooperation & Independent & $\begin{array}{l}\text { Teamwork } \\
\text { satisfaction }\end{array}$ & $\begin{array}{l}\text { Teamwork } \\
\text { processes }\end{array}$ \\
\hline WebCT & $-0.177^{\star}$ & & & & & & & & & \\
\hline Age & & $0.425^{\star *}$ & & & & & & & & \\
\hline Work & & $0.321^{\star *}$ & & & & & & & & \\
\hline Do & & & & $-0.958^{* *}$ & & & & & & \\
\hline Think & & & & & $-0.985^{\star \star}$ & & & & & \\
\hline Independence & & & & & & & $-0.493^{\star \star}$ & & & \\
\hline Integrating & $-0.247^{\star *}$ & & $0.320^{\star *}$ & & & & & & & \\
\hline Collectivism & $0.177^{\star}$ & & & & $-0.230^{*}$ & $0.203^{*}$ & $0.443^{* *}$ & & & \\
\hline Teamwork & & & & & & & $0.186^{\star}$ & & & \\
\hline \multicolumn{11}{|l|}{ Satisfaction } \\
\hline Teamwork & & & & & & & & $-0.251^{* \star}$ & $0.188^{*}$ & \\
\hline \multicolumn{11}{|l|}{ Processes } \\
\hline Use I-Lecture & & & & & & & & & & $0.207^{\star}$ \\
\hline
\end{tabular}

* Correlation is significant at the 0.05 level (1-tailed).

** Correlation is significant at the 0.01 level (2-tailed).

Note: Only significant correlations are presented for ease of interpretation. 


\section{Comparison between the student groups}

The next step was to compare results between the two groups. Satisfaction with their ability to manage the team was found to be slightly higher for the second group, and significant differences emerged with those in the second year of the study reporting less conflict and therefore, less reliance on team rules $(p \leq 0.001)$, and the conflict resolution procedure $(p \leq 0.005)$. Of interest was that students rated teamwork satisfaction significantly more highly in this course than in other courses $(p \leq 0.001)$. While acknowledging many variables could affect this result, it does provide support for the hypothesis that using a process to adapt and manage team processes and expectations positively affects the learning experience. These results are shown in Table 2.

A comparison between the two cohorts is presented in Table 3. Significant correlations exist between teamwork satisfaction, the ability to coordinate the team's activities and relationships and the effect of these on learning outcomes. Both cohorts valued having rules, conflict resolution processes and the review process as part of the action research process. Taken together these findings support the need to manage team learning and demonstrate the value of providing students with the skills and support to manage the process, lending further credence to the hypothesis.

Table 2 Comparison of student satisfaction with outcomes 2004/5

\begin{tabular}{lllll}
\hline End-of-semester feedback & \multicolumn{2}{c}{2004} & \multicolumn{2}{c}{2005} \\
\hline & Mean & SD & Mean & SD \\
\hline How satisfied were you with: & & & & \\
Experiences of teamwork in this course? & 4.08 & 0.98 & 4.11 & 0.92 \\
Experiences of teamwork overall & 3.94 & 0.74 & 3.79 & 0.84 \\
[in other courses]? & & & & \\
The amount of time spent on team projects? & 3.72 & 0.82 & 3.89 & 0.86 \\
Your ability to coordinate times for teamwork? & 3.57 & 1.03 & 3.86 & 0.88 \\
The membership of your team? & 3.71 & 0.96 & 4.01 & 1.06 \\
Your learning in the team setting? & 3.96 & 0.95 & 3.85 & 0.97 \\
Did having clearly articulated rules aid & 3.85 & 0.88 & 3.88 & 1.14 \\
your teamwork? & & & & \\
Did your team use team rules to help & 3.92 & 1.17 & 2.97 & 1.51 \\
manage your team? & & & & \\
Did your team use the conflict & 3.08 & 1.40 & 2.46 & 1.44 \\
resolution procedure? & & & & \\
\hline
\end{tabular}

Note: Significant changes are identified in Bold type. 
Table 3 Comparison of satisfaction outcome correlations for 2004 and 2005

\begin{tabular}{|c|c|c|c|c|c|c|c|c|c|}
\hline & 1 & 2 & 3 & 4 & 5 & 6 & 7 & 8 & 9 \\
\hline 1. Teamwork satisfaction & 1 & $0.362^{\star \star}$ & 0.101 & $0.404^{\star \star}$ & $0.446^{\star \star}$ & $0.725^{\star \star}$ & $0.554^{\star \star}$ & $0.198^{\star}$ & 0.024 \\
\hline 2. Teamwork other courses & $0.216^{*}$ & 1 & $0.470^{\star \star}$ & $0.361^{\star \star}$ & $0.253^{\star \star}$ & $0.336^{\star \star}$ & $0.354^{\star \star}$ & $0.274^{\star \star}$ & 0.125 \\
\hline 3. Team time & $0.454^{\star *}$ & $0.323^{\star \star}$ & 1 & $0.308^{\star \star}$ & -0.007 & $0.211^{*}$ & $0.265^{\star}$ & -0.032 & 0.104 \\
\hline 4. Coordinate & $0.345^{\star *}$ & $0.319^{\star \star}$ & $0.412^{\star \star}$ & 1 & $0.464^{\star \star}$ & $0.487^{\star \star}$ & $0.468^{\star \star}$ & 0.124 & 0.050 \\
\hline 5. Team members & $0.611^{* \star}$ & $0.243^{*}$ & $0.405^{\star \star}$ & $0.513^{\star *}$ & 1 & $0.443^{\star \star}$ & $0.382^{\star \star}$ & 0.128 & 0.080 \\
\hline 6. Learning & $0.666^{\star \star}$ & $0.261^{\star \star}$ & $0.372^{\star \star}$ & $0.463^{\star \star}$ & $0.613^{\star \star}$ & 1 & $0.595^{\star \star}$ & $0.241^{\star \star}$ & 0.000 \\
\hline 7. Benefit of having rules & 0.197 & 0.177 & $0.206^{\star}$ & $0.217^{\star}$ & $0.204^{\star}$ & $0.362^{\star \star}$ & 1 & $0.254^{* *}$ & 0.130 \\
\hline 8. Used teamwork rules & $0.229^{*}$ & 0.157 & $0.258^{* \star}$ & $0.258^{\star *}$ & $0.318^{\star \star}$ & $0.435^{\star \star}$ & $0.623^{\star \star}$ & 1 & $0.517^{\star \star}$ \\
\hline 9. Used conflict resolution & 0.185 & $0.270^{\star \star}$ & 0.092 & $0.238^{*}$ & 0.148 & $0.241^{\star}$ & $0.455^{\star \star}$ & $0.597^{\star \star}$ & 1 \\
\hline Use of I-lecture -2005 & -0.063 & -0.066 & -0.007 & -0.137 & -0.071 & -0.030 & $0.252^{\star}$ & $0.262^{\star \star}$ & $0.286^{\star \star}$ \\
\hline
\end{tabular}

Notes: * Correlation significant at 0.05 level (2-tailed). ${ }^{* \star}$ Correlation significant at 0.01 level (2-tailed).

2004 data in the upper right quadrant; 2005 data in the lower left quadrant 


\section{Discussion}

This study provides insights into how we can better manage team learning in the higher education environment. The approach used made students far more aware of the processes needed for successful teamwork and provided an opportunity for surfacing and dealing with minor problems before a team became dysfunctional. The high correlations between teamwork satisfaction, conflict management and having group rules and processes to manage the teamwork support the need to consider these issues when setting up teamwork projects. Similarly, the approach allowed students to understand the processes of teamwork and manage these, which in turn increased satisfaction with the course overall. Outcomes were not affected by age and whether working full-time or part-time. An unexpected finding was that access to online course materials, such as recorded lectures, helped clarify areas of disagreement and manage team conflicts. The fact that female students were more likely to take this route could be related to their significantly higher preferences for working collectively and integrating course content and learning outcomes than males. In addition, we found student satisfaction with teamwork and their ability to manage team processes were more effective in smaller team sizes than expected.

In previous years, we had assumed that a reasonable and manageable team size for semester-long projects would be four or five members. We also assumed that students would break up tasks, much as they do in industry. However, student feedback in the first year of the study indicated that breaking up the task had limited merit, as the team assignment required a high level of integration. This meant the students needed to deal with the logistics of managing multiple agendas in their personal lives and studies, as well as managing the group process well enough to integrate a complex task within a limited time period. Using our approach, the students identified that breaking up a complex interrelated task led to poorer performance and increased the risk of social loafing. Other researchers have also suggested that smaller group sizes reduce the risk of member incompatibility and social loafing (Butterfield and Pendegraft, 1996; Guerin, 2003). Based on feedback from the first year of the study, we heeded students' suggestion to keep the team size for the class projects to a maximum of four students per team the following year. Students also recommended some class time be allocated to help them plan for and manage task interdependence. We adopted these recommendations and, consequently, in the second year of the study, we found that conflict resolution and team rules were less important. In addition, students rated satisfaction with teamwork in this course significantly higher than in other courses. 
Some suggest that working through conflict in teams is a good learning experience for students; while we agree with this to a point, we think the negative experience of a dysfunctional group has limited value for teaching teamwork skills. Having a positive experience, particularly if students reflect on how to improve the team process, promotes learning practical strategies to help them adapt, change and manage their own and others' behaviour when they work in industry. For example, if students are encouraged to view unrealistic promises to perform as part of the forming stage, or conflict as part of the storming stage, then they can focus on this as being part of the process. In addition, reviewing their performance on an ongoing basis and identifying issues that inhibit performance teaches problem solving in a practical way, as well as promoting ownership. If we are to provide students with a useful and positive learning experience of working in a team, then we need to set this up in such a way as to enable teamwork satisfaction, successful conflict management and group rules and processes to manage the teamwork. The approach developed to help students successfully manage teamwork through this study is now described.

\section{Management of teamwork: strategies and processes to foster successful teamworking skills}

Throughout the semester, the teams regularly reviewed their progress and our focus was for students to understand that process and content are separate but convergent issues. The first workshop focused on team building with staff providing a team-building, problem-solving exercise. Students were also asked to identify past positive and negative experiences with teamwork and use these experiences and the team development models to guide them in developing their own ground rules. Teams self-selected and formed over the first couple of weeks but projects did not commence until week 5 . We think this is important because it gives students a sense of control so that they can better manage the logistics of team contributions outside the classroom. We used a 'barnraising' exercise where students could come forward and identify any specific criteria that they needed from their team members. For example, some students would list the hours they worked and when they could meet outside class times, others might request team members who were working toward achieving high grades. Throughout the semester students regularly contributed short team-building exercises, in the form of ice-breakers, role-plays and experiential exercises, which took no more than 10 minutes of class time. This process was maintained the following year, but more time was spent on discussing and 
exploring member roles, processes for managing the task and relationships, and dealing with potential conflicts during the review process.

Initially the reviews were conducted every two or three weeks; however, this increased to a weekly review as students became more pressured before the submission of a team assignment. The reviews combined content and process and usually took 10-20 minutes within a two-hour workshop. Teams were asked to identify what was working well and areas for improvement, and then use the action research approach to identify what strategies they could use to build on their strengths. Team members were also asked to take the devil's advocate role in assessing and reviewing their management strategies, their progress and any emerging problems or potential problems, so that these could be dealt with before member relations become strained. Without such a strategy to deal with problems, compliance can masquerade as cooperation and dysfunctional norms can quickly emerge to undermine the teams' ability to perform. Conflict management skills and strategies - even rudimentary ones - are essential for this to be effective.

We encourage students to view conflict as an opportunity to achieve two specific and distinct outcomes. Firstly, debate adds greater depth and richness to their understanding of content if they focus on the outcome. Secondly, conflict provides an opportunity to explore issues of process and renegotiate relationship and task boundaries. We teach the students simple conflict management strategies, such as 'Inform and Invite' (Dick, 1991) and to use 'I' statements, in preference to 'You' statements. The 'informinvite' strategy invites any team member who perceives a problem to explain this to the other members, before inviting contributions on how to resolve these problems. By combining feedback with I statement invitations, students avoid blaming or attacking other members and can focus on the issue. The students rated themselves highly in terms of their interpersonal, communication, leadership and problem-solving skills. This may be a perceptual bias on their part, as they know these are important skills to develop; nonetheless, this set a high expectation for their behaviour. Students were keen participants in the action research process and viewed the reflection and feedback process as a practical application of academic learning that would benefit them in the future. As suggested by Springer et al. (1999), they realize that this experience enriches their experience and self-esteem and prepares them for the workforce.

Another step that we took was the option of working independently and submitting an individual piece of work for assessment, if an individual student could present a case for this. This option was to accommodate students if it was difficult for them to work in a team. This could occur, for example, because a student had to travel because of work, or because of a 
medical condition. Only two mature-age students, who worked full-time, took this option. Giving students some options when they are facing extenuating circumstances is in line with employee involvement and empowerment strategies that are part of current workforce practice (Costello et al., 2002; Kotter and Cohen, 2002). Discussions with students identified that many valued the motivation and broadening of understanding gained from teamwork and this in turn benefited their grades. For this reason, students were generally happy to support team members in the case of short-term illness. Students had the choice of leaving a team, but they could take shared work they had contributed up to the time they left the group; however, this option could only be exercised after discussion with an instructor. In the first year of the study, two students did break away from their groups. One did so because she felt the others were not working to the level she required, and the second did so because of a change in work commitments. This first student subsequently rejoined her group two weeks later after an in-class discussion among the members during one of the review meetings. In the second year of the study, there were no breakaways from any of the groups. Students knew they could renegotiate the rules and processes if there was a good reason to do so and this option empowered and made them more thoughtful about their choice, rather than causing them to opt out. It was up to the students to hold the members accountable. In addition, a team could ask a non-performing member to leave, although this did not occur.

The team project included the analysis of a case study and facilitating a class discussion on that case, and was worth $35 \%$ of the total grade. Peer feedback was also a small component of the assessment so students knew they were accountable to their team members. The peer assessment of $5 \%$ provided feedback to teaching staff, who considered this when grading students' work. Students were asked to rate other members' contributions in terms of completing tasks as agreed and on time, attending team meetings if these were held, supplying work to an acceptable standard, carrying out their share of the work, showing initiative and helping the team to be effective as well as showing support for other team members. If needed, grade amendments were only made after staff discussed the result with the students concerned.

\section{Conclusion}

This article provides insights into dealing with teamwork in the university setting. We set out to improve students' understanding of how they could build successful relations in their teams, through developing their understanding of why members behaved as they did and how they could influence 
their own and others' behaviour to make the experience more positive. Our findings indicate that female students were more inclined to work collectively, with more emphasis on feelings or intuition and integrating learning, whereas male students viewed their roles as leaders, thinkers and problem solvers more positively. This suggests that mixed-gender teams might provide a better balance and could lead to more positive teamwork experiences for both genders. Overall, the results show that students see the value of teamwork and exercise positive choices when they have structured processes and are actively engaged in managing team relations. Allocating class time for planning and teamwork reviews and providing access to online learning technologies, such as recorded lectures that improve communication richness and clarity, help students manage the conflicting agendas they need to deal with and improves teamwork and learning satisfaction. More importantly, having rudimentary conflict resolution skills, knowledge of team development and the processes to manage team relations teaches and empowers students to manage team relations in a positive way and gives them practical skills to use when the enter the workforce as graduates.

There are limitations to the study described. The two samples were relatively small and might not have identified biases related to age, gender and culture. Although we found no differences between full-time students, part-time students and non-working students, this could be related to sample size and regional affects. Approximately $65-70 \%$ of students were engaged in paid work for 5-38 hours per week, so these groups may not be representative of other student cohorts. The participants were second-year management students who had a positive disposition towards a high level of interpersonal and communication skills. Our results may identify a selfserving bias that could be less likely to occur with students in other disciplines. We spent time in class on team-building activities and this is likely to have promoted better relations in the course. The course content focuses on the need for students to learn to deal with multiple contingency effects and a high level of ambiguity, so this approach is well suited to a management course, and we recognize this could be considered time-consuming or unsuited for some other disciplines or subject matter. Finally, if team membership is allocated by some other means than a self-selection basis, the outcome might also differ.

While our results suggest that the approach described above helped student develop positive team relations and team skills, further research is required to see if these results would transfer to other settings, particularly with larger cohorts. Online support helped students clarify information, guidelines and expectations, and further investigation of the role online support plays in improving communication might allow this support to be better targeted. Similarly, a better understanding of how much time should 
be devoted to team processes, and when and how this is best allocated, might assist educators who struggle with managing both process and content.

\section{Acknowledgements}

We thank both the anonymous referees and the Editor for the comments, support and constructive feedback.

\section{References}

ANDERSON, J. R. (2005) 'The Relationship Between Student Perceptions of Team

Dynamics and Simulation Game Outcomes: An Individual-level Analysis', Journal of Education for Business 81(2): 85-90.

BARnES, J. \& OWENS, L. (1992) Learning Preference Scales: Handbook and Test Master Set, Teachers, Students, Parents. Hawthorn, Victoria: Australian Council for Educational Research.

BILleTt, S. (2004) 'From Your Business to Our Business: Industry and Vocational Education in Australia', Oxford Review of Education 30(1): 13-35.

BROWN, D. R. \& HARVEY, D. (2006) An Experiential Approach to Organization Development, 7th international edition. Upper Saddle River, NJ: Pearson Education.

BUtTERFIELD, J. \& PENDEGRAFT, N. (1996). 'Gaming Techniques to Improve the Team-Formation Process', Team Performance Management 2(4): 11 http://proquest.umi.com/pqdweb?did=86922839\&Fmt $=7 \&$ clientId $=20829 \& \mathrm{R}$ $\mathrm{QT}=309 \& \mathrm{VName}=\mathrm{PQD}$ [accessed 11 February 2007].

COSTEllo, M. L., BRUNNeR, P. W. \& HASTY, K. (2002) 'Preparing Students for the Empowered Workplace: The Risks and Rewards in a Management Classroom', Active Learning in Higher Education 3(2): 117-27.

DiAmond, M. R. (2004) 'The Usefulness of Structured Mid-term Feedback as a Catalyst for Change in Higher Education Classes', Active Learning in Higher Education 5(3): 217-31.

DICK, B. (1991) Helping Groups to be Effective: Skills Processes and Concepts for Group Facilitation. Brisbane, Queensland: Interchange.

GERSICK, C. J. G. (1991) 'Revolutionary Change Theories: A Multilevel Exploration of the Punctuated Equilibrium Paradigm', Academy of Management Review 16(1): 10-36.

GUERIN, B. (2003) 'Social Behaviors as Determined by Different Arrangements of Social Consequences: Diffusion of Responsibility Effects With Competition', Journal of Social Psychology 143(3), 313-29.

HAIR, J. F. JR, ANDERSON, R. E., TATHAM, R. L. \& BLACK, W. C. (1998) Multivariate Data Analysis, 5th edn. Englewood Cliffs, NJ: Prentice-Hall.

HONEY, P. \& MUMFORD, A. (1995) Using Your Learning Styles, 2nd edn. Maidenhead, Berkshire: Peter Honey.

KAHN, W. A. (1995) 'Group Process Checkpoints for Team Learning in the Classroom', Journal of Policy Analysis and Management 14(2): 310-26.

KARAU, S. J. \& HART, J. W. (1998) 'Group Cohesiveness and Social Loafing: Effects of a Social Interaction Manipulation on Individual Motivation within Groups', Group Dynamics:Theory, Research and Practice 3: 185-91.

KNABB, M. T. (2000) 'Discovering Teamwork: A Novel Cooperative Learning Activity to Encourage Group Interdependence', American Biology Teacher 62(3): 211-13. 
KOLB, D. A. (1984) Experiential Learning: Experience as the Source of Learning and Development. Englewood Cliffs, NJ: Prentice-Hall.

KOTTER, J. P. \& COHEN, D. S. (2002) 'Creative Ways to Empower Action to Change the Organization: Cases in Point', Journal of Organizational Excellence 22(1): 73-82.

KUIT, J. A., REAY, G. \& FREEMAN, R. (2001) 'Experiences of Reflective Teaching', Active Learning in Higher Education 2(2): 128-42.

LOU, Y., ABRAMI, P. C., SPENCE, J. C., POUlSEN, C., CHAMBERS, B. \& D'APOllonia, S. (1996) 'Within-class Grouping: A Meta-analysis', Review of Educational Research 66(4): 423-48.

LUSSIER, R. \& POUlOS, M. (1998) Organisational Behaviour: A Skill Building Approach. Roseville, NSW: Irwin/McGraw-Hill.

MCFEeters, F. (2003) 'The Effects of Individualism Vs. Collectivism on Learners' Recall, Transfer and Attitudes Toward Collaboration and Individualized Learning'. Unpublished $\mathrm{PhD}$ thesis in Curriculum and Instruction (Instructional Technology), Virginia Polytechnic Institute and State University, Blacksburg, VA.

mCShane, s. \& TRAVAglione, T. (2005) Organizational Behaviour on the Pacific Rim, enhanced edition. Roseville, NSW: McGraw-Hill.

MUMFORD, A. (1995) 'Putting Learning Styles to Work: An Integrated Approach', Industrial and Commercial Training 27(8): 28-35.

MUTCH, A. (1998) 'Employability or Learning? Groupwork in Higher Education', Education \& Training 40(2/3): 50-6.

OHL, T. \& CATES, W. (2006) 'The Nature of Groups: Implications for Learning Design', Journal of Interactive Learning Research 17(1): 71-89.

PORTWOOD, M. M. (1999) 'The Experience of Students in a Collaborative Learning Classroom'. Unpublished EdD thesis, University of Tennessee, USA.

RAHIM, M.A. (1983) 'A Measure of Styles of Handling Interpersonal Conflict', Academy of Management Journal 26 (June): 368-76.

SPRINGER, L., STANNE, M. E. \& DONOVAN, S. S. (1999) 'Effects of Small-group Learning on Undergraduates in Science, Mathematics, Engineering, and Technology: A Metaanalysis', Review of Educational Research 69(1): 21-51.

TRIANDIS, H. C. (1995) Individualism and Collectivism. Boulder, CO: Westview Press. TUCKMAN, B. W. \& JENSEN, M. A. C. (1977) 'Stages of Small Group Development Revisited', Group and Organizational Studies 2(4): 419-27.

TOWNS, M. H., KREKE, K. \& FIELDS, A. (2000) 'An Action Research Project: Student Perspectives on Small-group Learning in Chemistry', Journal of Chemical Education 77(1): 111-15.

WAGEMAN, R. (1999) 'Task Design, Outcome Interdependence, and Individual Differences: Their Joint Effects on Effort in Task-performing Teams', Group Dynamics: Research, Theory and Practice 3(2):132-7.

WAGEMAN, R. \& FREDERICK, M. G. (2005) 'As the Twig is Bent: How Group Values Shape Emergent Task Interdependence in Groups', Organization Science 16(6): 687-722.

WAGNER, J. A., III (1995) 'Studies of Individualism-Collectivism: Effects on Cooperation', Academy of Management Journal 38(1): 152-72.

YAZICI, H. J. (2005) 'A Study of Collaborative Learning Style and Team Learning Performance'. Education \& Training 47(2/3): 216-29. 